\title{
Knowledge Transfer in Firms under the Promotion of Dynamic Capability Research
}

\author{
Pengyu Jiang \\ School of Management, Jinan University, Guangzhou, China \\ Email:381083893@qq.com
}

Received 14 August 2015; accepted 8 September 2015; published 11 September 2015

Copyright () 2015 by author and Scientific Research Publishing Inc.

This work is licensed under the Creative Commons Attribution International License (CC BY). http://creativecommons.org/licenses/by/4.0/

(c) (i) Open Access

\begin{abstract}
This paper aims at regarding knowledge transfer as the basis of improving firm performance in knowledge economy society, and analyzing the effects of knowledge transfer on firm performance from the perspective of dynamic capability. Thus, this paper gives firm some suggestions to achieve knowledge transfer and the update of knowledge system through integrating internal and external resources, and to build the core competitiveness and even improve its firm performance.
\end{abstract}

\section{Keywords}

Knowledge Transfer, Dynamic Capability, Firm Performance

\section{Introduction}

With the rapid development of science and technology, the external environment that firms face with constantly changes and intensifies the competition among firms. Only by integrating and optimizing resources both internal and external, constantly learning and continuously improving, can firms produce sustained competitiveness. Competitions between many firms will be concentrated in the comprehensive knowledge capacity in the future. Knowledge, as the key element to form different firm heterogeneity and core resource capacity, its process of accumulation not only relies on their own, but also relies on the interaction with external knowledge to promote the update and acquisition of knowledge, and relies on collaborating with partners in their value network to complete the knowledge transfer both within firm and between firms.

Conner and Prahalad (1996) proposed that the differences of performance between different firms were caused by the differences of the value of knowledge and the capability of knowledge integration and application [1]. The purpose of knowledge transfer is to assimilate and utilize new knowledge effectively, and accelerate the application of knowledge that benefits firms, so that firms can gain the competitive advantage to improve firm in the end. Because of the importance for knowledge accumulation, knowledge transfer activities play an important 
role in the cultivation of the core capability and the promotion of firm performance.

With the constant changes of the external environment, firms also should pay attention to opportunity catch and resources integration, and reconstruction of organization during knowledge transfer. And dynamic capability is considered as an ability to achieve a series of organization and management process, including the capability to identify, build, learn and integrate internal and external resources in firm, having great significance in business management practice. So, this article focuses on the dynamic capability, trying to build the influences that knowledge transfer has on firm performance.

\section{Knowledge Transfer Concept and Definitions}

American scholar Teece (1977) first proposed the concept of knowledge transfer, he thinks that firm can accumulate more applied knowledge from different countries through technology transfer between multinational companies [2]. Kogut and Zander (1992) point that the ability to transfer knowledge is an important factor for the existence and development of firm, effective knowledge transfer is very important for firms to improve their competition advantage [3].

According to the definition of knowledge transfer in different angle of scholars in literature, there are a variety of concepts about knowledge transfer activities, these can be summarized as following three categories basically. The first stresses transfer process of knowledge content. Such as Garavelli (2000) defines it as knowledge exchange between the knowledge transmitter and recipient, thinking that coding and interpretation make up the whole process of knowledge transfer and coding is knowledge dissemination while interpretation is absorption in knowledge transfer activities [4]. Argote and Ingram (2000) emphasize that knowledge transfer is the process that organizations transfer knowledge through different channels to implement organizational knowledge sharing and effectively utilize the existing knowledge [5]. The second emphasizes the gains of knowledge transfer subject on both sides. They argue that the knowledge transfer is a process, in which a subject is affected by another, and this subject can be individuals, teams, departments, and even firms. Sue Newell et al. (2002) regard that knowledge transfer can realize performance improvement through continuously accumulating and reusing the unique knowledge of employees and groups within the organization [6]. Dong Xiaoying, a domestic scholar, considers that knowledge transfer is the process to apply effective knowledge or skills proved by practice in the different environment to enhance the production and the applied scale of knowledge, and points out that knowledge transfer emphasize the new changes in the process [7]. The third combines the above two aspects, it focus more on application and benefits of knowledge as well as emphasizes the process of knowledge dissemination at the same time, it also points out that the key factor of knowledge transfer is the movement and application of knowledge, knowledge transfer is not only the formation of a channel to exchange knowledge, but also the process to absorb and create new knowledge. Zuo Meiyun (2003) introduces, knowledge transfer is the process, in which the subject in high intellectual potential energy transfer knowledge to others in low intellectual potential energy. This process is accompanied by the assignment of knowledge use value, generally leads to corresponding returns. The more the number of knowledge are, the higher knowledge quality is, knowledge structure will be more reasonable and the intellectual potential energy will be higher [8].

This paper argues that knowledge transfer is the process that firms integrate internal and external resources in the management, achieve the update of their knowledge system and the growth of performance through the absorption and utilization of knowledge needed for their own development, to adapt to the competitive environment and the changes of strategic goals. Therefore, the capability of knowledge transfer will become the key factor to adapt to dynamic environment changes and improve enterprise performance in firms.

\section{The Influences of Knowledge Transfer on Firm Performance}

With the continuous improvement of global economic integration and international competition is increasingly fierce, firms create and explore knowledge on their own, as well as meet the needs of their developments through continuously learn and acquire new knowledge. It is the transfer and transformation of knowledge between different firms that makes them exert their great economic values. Through obtain and make use of new knowledge, firms effectively reduce the operating costs, innovate the ways of operation and profit, to promote firm performance. The capacity of knowledge transfer in firms determines the space of the growth and development of firms to a large extent.

Argote, Ingram and Levine (2000) argue [5], no matter what kind of background based on, knowledge suc- 
cessfully transfer to the receiving party will bring the improvement of the knowledge receiver's capacity and firm performance. Davenport and Prusak (1998) think [9], knowledge transfer is the process to transfer knowledge from the knowledge source to other department or organization, including the transfer and absorption two dimensions. Knowledge are obtained and then absorbed, only by the absorber grasps and applies the knowledge actually, can the process of transfer knowledge be successful and can improve its firm performance.

The knowledge transfer should include the whole process from the knowledge acquisition to knowledge application, so this paper analyzes the influences of knowledge transfer on firm performance from two aspects that knowledge acquisition and knowledge utilization.

\subsection{Knowledge Acquisition and Firm Performance}

Knowledge acquisition is the process to search, identify, acquire and grasp the external new knowledge through a certain way when firm contacts with the external knowledge sources. Knowledge acquisition includes the search and selection for internal and external knowledge, as well as the gain of new knowledge through various channels and the promotion for knowledge transfer.

Knowledge acquisition measures whether the knowledge can be absorbed, acquired and grasped. The availability of knowledge is the precondition of successful knowledge transfer, knowledge has the potential to be applied and even promote the firm performance only after acquired. Therefore, as the basis and premise of knowledge utilization, knowledge acquisition affects firm performance under the function of knowledge utilization to some extent.

\subsection{Knowledge Utilization and Firm Performance}

Knowledge utilization is the process to integrate the knowledge gained or transformed in transfer with the existing knowledge effectively and to generate new knowledge, improve the firm process or performance.

Knowledge utilization measures whether the receiver can take advantage of the knowledge after acquisition. If it because of knowledge configuration, or the knowledge acquired have not been fully developed and transformed temporarily, or the firm's existing ability is not enough to absorb and utilize knowledge and so on, in the conditions knowledge are only acquired but not utilized, so it is not enough to improve firm performance. Therefore, the ultimate goal of knowledge transfer lies in the creation and reuse of knowledge, only the knowledge can be utilized, can the receiving firm improve its performance finally.

\section{Knowledge Transfer under the Promotion of Dynamic Capability}

The concept of dynamic capability is put forward by Teecein 1994. Teece, Eisenhardt and Martin (2007) etc. argue that dynamic capability is a kind of abstract capability, which firms to complete the organization and management process, including the ability to identify, to build, to integrate, to learn and to reconstruct for internal and external resources of firm [10].

In the existing studies, more and more scholars believe that dynamic capability is a kind of abstract capability to change the ability of firms, it is a more advanced capability. On the frame of dynamic capability, Wu (2010) proposes [11], resource integration and coordination capability, organization reconstruction capability are important parts of the dynamic capability, and with the focus of the strategic management field on dynamic capability, opportunity recognition capability begins to be regarded as a part of dynamic capability by more and more scholars. O’Reilly and Tushman (2008) suggest [12], opportunity recognition capability is the foundation that firm responds to the changes of external environment, implement resource integration and organization reconstruction. The three capabilities constitute the core competence of firm strategy management.

Since the diffusion of knowledge is very fast and widespread, firms should understand thoroughly the trend of market development, pay attention to the appearance of new technologies and products, capture new market opportunities timely and find unsatisfied needs and market segment during the process of knowledge acquisition and knowledge utilization, thus to determine market strategy. It is also the direction and motivation of knowledge transfer. Once firms enter the new target market, they need to integrate internal and external resources, update the existing knowledge system and restructure the value network by learning and innovation, find new profit point to realize their values. When firms enter the late life cycle, their ability of learning and resource integration degenerate, even the system of the firm culture and organizational structure limit new knowledge 
transfer into, so firms should change and reform timely to innovate the business model.

Dynamic capability can promote the process of knowledge transfer greatly, the process from knowledge acquisition to utilization and to translate into the competitive advantage is also completed by the driving of the dynamic capability. Based on this, the article divides dynamic capability into opportunity recognition capability, resource allocation capability and organization reconstruction capability three dimensions, and builds the knowledge transfer model under the promotion of dynamic capability as shown in Figure 1, revealing the knowledge transfer acts as the key factor to improve firm performance under the promotion of dynamic capability.

\subsection{The Promotion of Opportunity Recognition Capability}

Opportunity recognition capability makes firm accurately grasp the change of external environment and the demand of market, timely absorb and learn advanced technical knowledge of industry, improve their products and services. And the firms with strong opportunity recognition capability can also explore and discover the new target market, guide the customer needs, introduce the new technology for products or adopt the new marketing model, create new values and open up new market space to improve firm performance.

Opportunity recognition capability contributes firm to promoting its improvement of strategic resources and organization process. Zhou (2010) researches and surmises [13], opportunity recognition capability make it easier for firms to obtain all kinds of new knowledge, including the new development of industrial technology, the new form of organizational reform, the new marketing model and marketing ideas, all these new knowledge integrated into existing business model, can effectively facilitate the improvement of the internal process and the promotion of competitive advantage.

\subsection{The Promotion of Resource Integration Capability}

Resource integration capability emphasizes that firms can adapt to the changes of external environment, constantly input, transfer and utilize external knowledge to allocate resources, achieve growth and improve firm performance through factor synergy effect. In the process of knowledge transfer, the stronger the resource integration capability is, firms can find the more ways of resource integration, establish the more effective way of resource substitution, discover the more widespread external resources, achieve the more effective transfer to improve firm performance.

Gilbert (2005) proposes [14] that, on the one hand, new technology and knowledge will spread quickly within

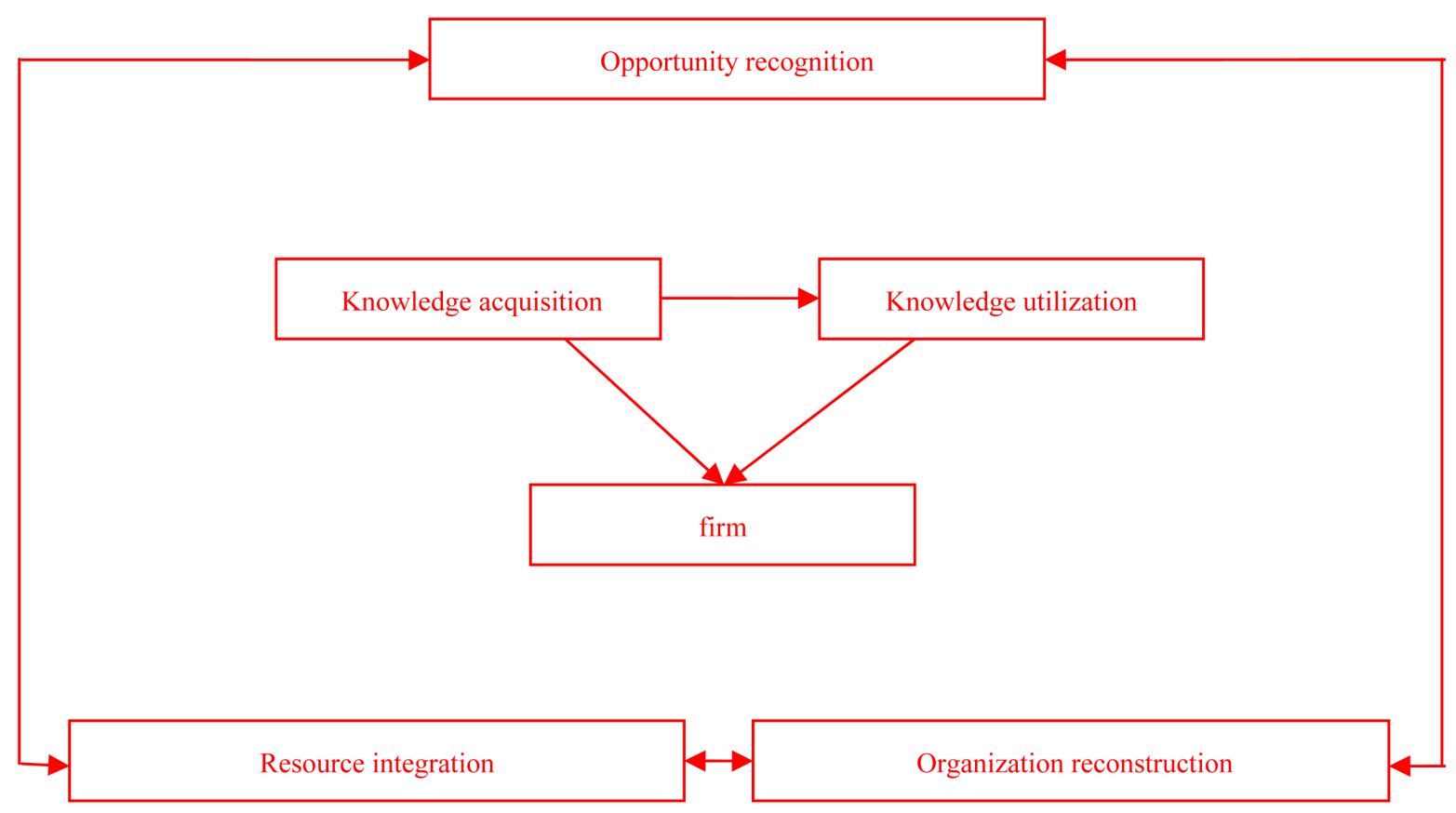

Figure 1. Knowledge transfer model under the promotion of dynamic capability. 
firms, while resource integration capability emphasizes that combine the existing knowledge and technology with the external knowledge and technology, facilitating firms to absorb and utilize, to realize the improvement of efficiency and performance. On the other hand, technical changes causes a rapid alternation of external knowledge and technology, resource integration capability can enhance coordination of firms, to make firms cope with the marketing competition in dynamic environment well through collaborating with external partners and knowledge transfer, and maintain their sustainable competitive advantages.

\subsection{The Promotion of Organization Reconstruction Capability}

Organization reconstruction capability can help firms timely change the structure of resource, technology and knowledge, achieve the matching among various sorts of knowledge factors and improve firm performance. Organization reconstruction capability changes the existing business model mean while advocating innovation culture in firms to accept the new technology and knowledge, thus to design new value propositions and profit points. The stronger organization reconstruction capability is, the more favorable for firms to improve the existing process and structure, to facilitate the communication of new knowledge within organizations and build efficient operation model.

Teece (2007) argues [10] that organization reconstruction capability fundamentally changes the existing structure of products, processes and organization relationship, and breaks the consistency of existing products and services, operation process and organization structure, it affects the operation model usually accompanied by the changes of revenue model and the redistricting of target market.

\section{Conclusions}

This article focuses on that firms improve performance through knowledge transfer activities in the background of knowledge economy era, and introduces the concept of dynamic capability. It emphasizes that knowledge acquisition and knowledge utilization can bring performance improvement to firms and it builds the knowledge transfer model under the promotion of dynamic capability. It also suggests that firms achieve knowledge update and performance improvement from opportunity identification, resource integration and organization reconstruction these three aspects, and give firms inspiration to complete knowledge transfer under the environment uncertainty.

Future research can pay more attention to the empirical study about the influences of knowledge transfer on firm performance, deeply explain the influence mechanism and path between knowledge transfer and firm performance, and analyze the factors influencing on the consequence of knowledge transfer, as well as the obstacle and the breaking measures in the process, to provide more guidance for business management practice.

\section{References}

[1] Conner, K.R. and Prahalad, C.K. (1996) A Resource-Based Theory of the Firm: Knowledge versus Opportunism. Organization Science, 7, 477-501. http://dx.doi.org/10.1287/orsc.7.5.477

[2] Teece, D.J. (1977) Technology Transfer by Multinational Firms: The Resource Cost of Transferring Technological Know-How. The Economic Journal, 87, 242-261. http://dx.doi.org/10.2307/2232084

[3] Kogut, B. and Zander, U. (1992) Knowledge of the Firm, Combination Capability and the Replication of Technology. Organization Seience, 3, 383-394. http://dx.doi.org/10.1287/orsc.3.3.383

[4] Garavelli, A.C. and Gorgoglione, M.S. (2002) Managing Knowledge Transfer by Knowledge Technologies. Technovation, 22, 269-279. http://dx.doi.org/10.1016/S0166-4972(01)00009-8

[5] Argote, I.P. (2000) Knowledge Transfer: A Basis for Competitive Advantage in Firms. Organizational Behavior and Human Decision Processes, 82, 150-169. http://dx.doi.org/10.1006/obhd.2000.2893

[6] Newell, S. (2002) Managing Knowledge Work and Innovation. Palgrave, New York, 15-28.

[7] Dong, X.Y. (2002) The Knowledge Transfer in the Process of Firm Informatization: The Case of Lenovo Group. Global Management Review, 11, 28-35.

[8] Zuo, M.Y. (2003) Knowledge Transfer in Firm Informatization. China Management Informationization, 10, 10-11.

[9] Davenport, T.H. and Prusak, L. (1998) Working Knowledge: How Organizations Manage What They Know. Harvard Business School Press, Boston, 16-78.

[10] Teece, D.J. (2007) Explicating Dynamic Capabilities: The Nature and Microfoundations of (Sustainable) Enterprise 
Performance. Strategic Management Journal, 28, 1319-1350. http://dx.doi.org/10.1002/smj.640

[11] Wu, L.Y. (2010) Applicability of the Resource-Based and Dynamic-Capability Views under Environmental Volatility. Journal of Business Research, 63, 27-31. http://dx.doi.org/10.1016/j.jbusres.2009.01.007

[12] O’Reilly, C.A. and Tushman, M. (2008) Ambidexterity as a Dynamic Capability: Resolving the Innovator's Dilemma. Research in Organizational Behavior, 28, 185-206. http://dx.doi.org/10.1016/j.riob.2008.06.002

[13] Zhou, K.Z. and Li, C.B. (2010) How Strategic Orientations Influence the Building of Dynamic Capability in Emerging Economies. Journal of Business Research, 63, 224-231. http://dx.doi.org/10.1016/j.jbusres.2009.03.003

[14] Gilbert, C.G. (2005) Unbundling the Structure of Inertia: Resource versus Routine Rigidity. Academy of Management Journal, 48, 741-763. http://dx.doi.org/10.5465/AMJ.2005.18803920 